EGU2020-9127

https://doi.org/10.5194/egusphere-egu2020-9127

EGU General Assembly 2020

(c) Author(s) 2021. This work is distributed under

the Creative Commons Attribution 4.0 License.

\title{
Identifying source regions at the Princes Elisabeth station in Antarctica, using dispersion modelling tools: a case study
}

\author{
Karen De Causmaecker ${ }^{1}$, Alexander Mangold ${ }^{1}$, Christophe Walgraeve ${ }^{2}$, Preben Van Overmeiren ${ }^{2}$, \\ Nadine Mattielli ${ }^{3}$, Stefania Gili ${ }^{3}$, and Andy W. Delcloo ${ }^{1}$ \\ ${ }^{1}$ Royal Meteorological Institute of Belgium (RMI), Ukkel, Belgium \\ ${ }^{2}$ Research group EnVOC, Ghent University, Ghent, Belgium \\ ${ }^{3}$ Laboratoire G-time, Université Libre de Bruxelles, ULB, Brussels, Belgium
}

During the time period December 2019 - January 2020, a lot of biomass burning has been ongoing in the Southern Hemisphere. This led to a large amount of fine dust being emitted and transported into the atmosphere of the Southern Hemisphere.

With the dispersion model FLEXPART, we will simulate these fires, using the CAMS Global Fire Assimilation System (GFAS) which assimilates fire radiative power (FRP) observations from satellitebased sensors in order to reproduce daily estimates of biomass burning emissions. Also information on the injection height is available.

Aerosol fluxes and sources in Antarctica and its closely associated Southern Ocean are poorly constrained, in particular the particle chemistry. A detailed understanding of present-day atmospheric transport pathways of particles and of volatile organic compounds (VOC) from source to deposition in Antarctica remains essential to document biogeochemical cycles and the relative importance of natural and anthropogenic compounds. Within the CHASE project (chase.meteo.be), the Royal Meteorological Institute of Belgium, Ghent University and the Université Libre de Bruxelles are doing research at the Belgian research station Princess Elisabeth $\left(71.9^{\circ} \mathrm{S}, 23.3^{\circ} \mathrm{E}\right.$; East Antarctica, Dronning Maud Land) on the physical-chemical composition of both atmospheric particles, particles in surface snow particles as well as of VOCs. Since 2018, samples are taken both near the Belgian research station Princess Elisabeth (active sampling with pumps) and on a transect to the coast (passive samplers and surface snow samples).

In this contribution we will thoroughly investigate the atmospheric transport pathways of the recent biomass burning plumes, and in particular to what extent parts of these plumes have reached Antarctica. The measured chemical signatures of atmospheric particles and VOCs will help to constrain the simulations of the dispersion model. 